\title{
Why did other European astronomers not see the December 1639 transit of Venus?
}

\author{
David W. Hughes \\ Department of Physics and Astronomy, The University, Sheffield, S3 7RH \\ email: d.hughes@sheffield.ac.uk
}

\begin{abstract}
The December 1639 transit of Venus was only seen and recorded in Much Hoole and Salford, Lancashire, England. It was visible, however, from all over Italy, France, Spain and Portugal. But no one was looking. This paper suggests reasons why.
\end{abstract}

\section{Introduction}

Imagine the scene. It is a typical cloudy day in late-autumnal Lancashire. In the mid-afternoon of Sunday, 4 December 1639 (Gregorian Calender, New Style = N.S.), equivalent to Sunday, 24 November 1639 (Julian Calendar, Old Style = O.S.) Jeremiah Horrocks (1618 - 1641) in Much Hoole, a village about 15 miles north of Liverpool, and William Crabtree $(1610$ - 1644) in Broughton near Manchester, 25 miles to the east of Horrocks' location, observe Venus starting to transit the solar disc. They were the only two on Earth who recorded observations of this rare event. Why? Considering that half our planet was pointing towards the Sun at the time (see Fig. 1), we can reasonably ask why about $50 \%$ of the population were ignoring what was going on. Let us consider a few possibilities.

(1) Only Horrocks and Crabtree knew about it. This is a reasonable supposition. Horrocks, a young Liverpudlian biblical clerk and children's tutor, with a fascination for astronomy in general and astronomical tables in particular, had only calculated that a transit would occur about a month before the event. In the Rudolphine Tables, of 1627, the German astronomer Johannes Kepler (1571 - 1630) had predicted that Venus would cross the Sun on 6 December 1631, and again in 1761. Unfortunately it was night-time in Europe at the time of the 1631 transit. After leaving Cambridge the young Horrocks amused himself by computing ephemeredes using Lansbergius' Tables. He soon realised that these tables were somewhat erroneous. However, using these tables, in conjunction with the Rudolphine Tables, enabled him not only to confirm Kepler's prediction that transits were spaced by about 120 years, but also to discover that they usually occurred in pairs, early December 1631 and 1639; early June 1761 and 1769; early December 1874 and 1882; early June 2004 and 2012, and so on.

In early November (N.S.) Horrocks predicted that in a mere four weeks there would be another Venus transit, on 4 December 1639. Four weeks was far to short an interval for news of this prediction to percolate even down to London, never mind across the Channel. And 1639 was before the foundation of the great scientific societies (Florence 1657, London 1662, Paris 1666). News travelled slowly. Scientific journals were unheard of. It was also at a time before the great observatories (Leiden 1632, Copenhagen 1637, Paris 1667, Greenwich 1675) produced a step function in the number of working astronomers.

Let us also speculate as to Horrocks' confidence in his prediction. Venus transits occur at inferior conjunction. Horrocks' prediction of the time of the 1639 Venus inferior 
Table 1. Prominent scientists around the time of the 1639 transit.

\begin{tabular}{|c|c|c|c|}
\hline Name & Birth/Death & Age at transit & Country or Place \\
\hline Elias Ashmole & $1617-1692$ & 22 & \\
\hline Adrien Auzout & $1622-1691$ & 17 & \\
\hline Isaac Barrow & $1630-1677$ & 9 & \\
\hline Ismael Boulleau & $1605-1694$ & 34 & France \\
\hline Robert Boyle & $1627-1691$ & 12 & \\
\hline John Cutler & $1608-1693$ & 21 & \\
\hline Ren Descartes & $1596-1650$ & 43 & Holland \\
\hline Giovanni Domenico Cassini & $1625-1712$ & 12 & Genoa \\
\hline Johannes Fabricus & $1587-$ & 52 & \\
\hline Galileo Galilei & $1564-1642$ & 75 & Florence \\
\hline Pierre Gassendi & $1592-1655$ & 47 & Paris \\
\hline William Gascoigne & $1612 ?-1644$ & 27 & London \\
\hline James Gregory & $1638-1675$ & 1 & \\
\hline Johannes Hevelius & $1611-1687$ & 28 & Gdansk \\
\hline Robert Hooke & $1635-1703$ & 4 & \\
\hline Jeremiah Horrocks & $1619-1641$ & 20 & Much Hoole \\
\hline Christiaan Huygens & $1629-1695$ & 10 & den Hague \\
\hline Gottfried Kirch & $1639-1710$ & 0 & \\
\hline Germiniano Montanari & $1633-1687$ & 6 & \\
\hline Jonas Moore & $1610-1679$ & 29 & London \\
\hline Robert Moray & $1608-1673$ & 31 & \\
\hline Blaise Pascal & $1623-1662$ & 16 & \\
\hline Giovanni B. Riccioli & $1598-1671$ & 41 & Bologna \\
\hline Christoph Scheiner & $1575-1650$ & 64 & Vienna / Nysa \\
\hline Christopher Towneley & $1604-1674$ & 35 & \\
\hline Seth Ward & $1617-1689$ & 22 & \\
\hline Godefroy Wendelin & $1580-1660$ & 49 & Bruxelles \\
\hline John Wilkins & $1614-1672$ & 25 & \\
\hline Christopher Wren & $1632-1723$ & 7 & \\
\hline
\end{tabular}

conjunction differed from those in other tables. Most gave the time as being hours sooner than he had calculated. Some even predicted that it would take place on the previous day (see Ferguson 1803). Horrocks not only observed the Sun on the Saturday, he also observed on Sunday from dawn, in case he might miss it. He might have thought, at the tender age of 20, that it was somewhat presumptuous to send his prediction to those more senior (and superior) members of the English intelligentsia with astronomical leanings, people with whom he was unacquainted. Sending letters in those days was not inexpensive and he might have thought it somewhat cheeky to write to the likes of Elias Ashmole (1617 - 1692), John Cutler (1608 - 1693), Jonas Moore (1610 - 1679), Robert Moray (1608 - 1679), Christopher Towneley (1604 - 1674), Seth Ward (1617 - 1789) and John Wilkins $(1614-1672)$. It seems that the only letter he wrote on the subject was to his close friend William Crabtree.

(2) No one else was observing the Sun. Let us consider the European astronomical scene. Fig. 2 shows an expanded version of Fig. 1. In the region to the right of the bold line the Sun had set before transit started. Observers just to the left of the line would have been able to see the disc of Venus on the eastern limb of the Sun at sunset. Due to the absorption of sunlight in the Earth's atmosphere, and the size of the disc of Venus (just over one minute of arc in diameter), this could have been detected by the naked eye. The further one moves to the left of the bold line (i.e. westward) the longer the transiting Venus would have been in view. Horrocks, for example, first caught a glimpse 


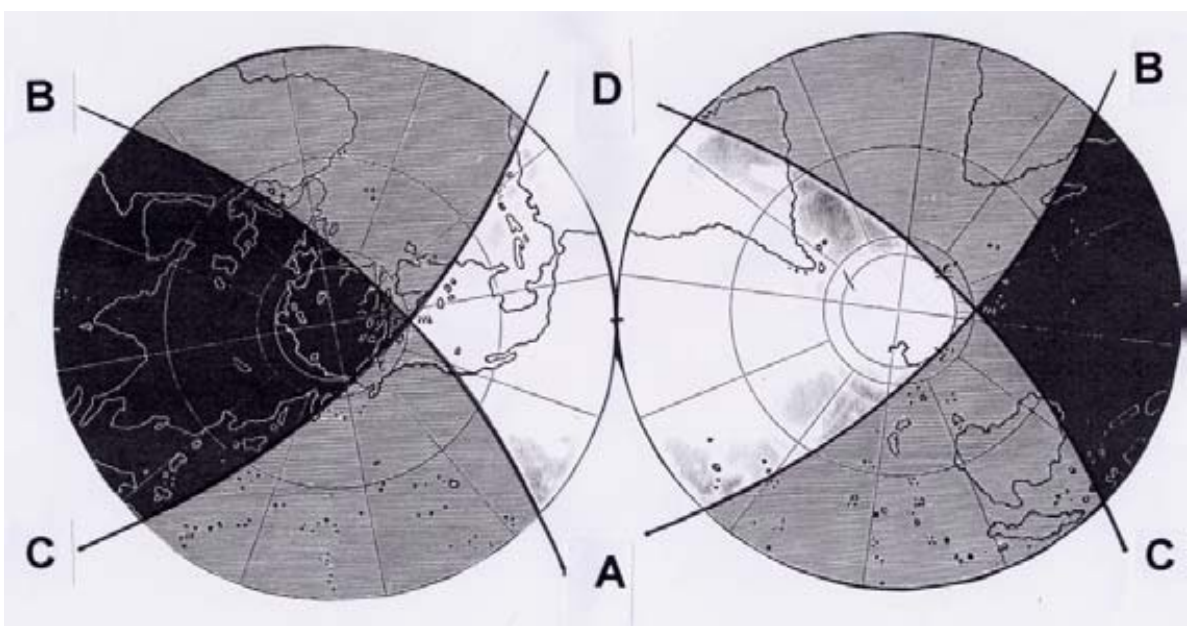

Figure 1. The visibility of the transit of December 1639. Everyone above the two lines marked $\mathrm{AB}$ would have been able to see the start of the transit. This region includes a considerable portion of Africa and western Europe and very nearly the whole of North and South America. Everyone below the lines marked CD could see the end of the transit. (This figure has been adapted from Plate III in Transits of Venus by R. A. Proctor, published by R. Worthington and Co., New York, 1875).

at $3: 15 \mathrm{pm}$, and made other observations at 3:35 and 3:45. He noted that the Sun set at 3:50 (see, for example, Ferguson 1803, p. 497) this being about 5 minutes after the Sun had a solar zenith angle of $90^{\circ}$, due to atmospheric refraction). These times would have been 'Hoole' local time. The equation of time was about +3 minutes and it would take the Sun about 11.5 minutes to travel the $2.9^{\circ}$ longitude west to Hoole, from the Greenwich meridian.

Fig. 2 shows that astronomers in places like Paris, Marseilles and Genoa would have had a similar amount of pre-sunset transit time as did Horrocks and Crabtree. Unfortunately, as one moves to the more favourable observing locations, such as Dublin, Barcelona, Madrid and Lisbon, astronomers become rather thin on the ground.

In the quest for 'other observations of the 1639 transit', one should really concentrate on the solar observers. This field was suffering from one of the typical astronomical lulls that often occur after a fast start. The work of Johannes Fabricius (1587 - ; the Frisian astronomer who wrote De maculis in sole observatis 1611), Galileo Galilei (1564 - 1642, who wrote three letters about sunspots in 1613; see Istoria e Dimostrazioni intorno alle Macchie Solari), John Greaves (1602 - 1652, Savilian Professor of Astronomy at Oxford University), Thomas Harriot (c1560 - 1621, England's first telescopic observer) and Christoph Scheiner (1573 - 1650, German professor at University of Ingolstadt) revolutionised solar astronomy. Sunspots were discovered to be actual 'blemishes' on the solar photosphere, even though Scheiner for many years thought that they were orbiting inner planets. Most early astronomers observed the Sun by projecting the solar image onto a white screen placed a convenient distance behind the eyepiece of their refracting telescopes. This was the approach used by Horrocks. Fig. 3 shows the Scheiner observing system. Interestingly, this image was shown to the artist Ford Madox Brown (1821 1893) when he was commissioned in 1880 by the city of Manchester to paint a mural of Crabtree observing the transit of 1639 (see Knobel 1903 and Wolf 1968), and he used it as a basis of his painting. Fig. 4 shows the helioscope used by Scheiner. A representation of this equatorial Keplerian telescope was incorrectly used in the Eyre Crowe 


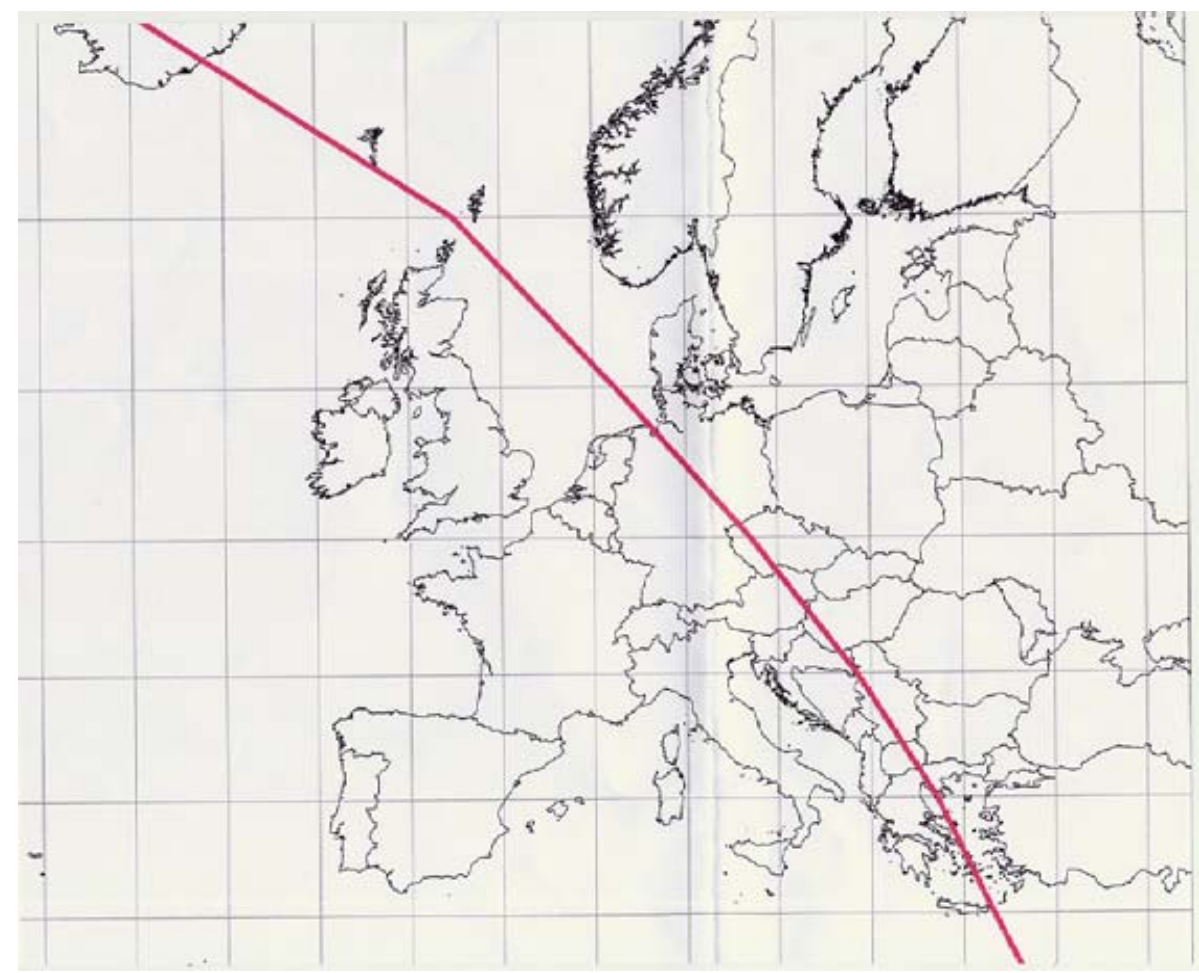

Figure 2. The European part of Fig. 1. The bold line across the diagram indicates the places where the solar altitude is $0^{\circ}$ at the time of first contact $\left(t_{1}\right)$. This line passes through the following points, (Latitude North; Longitude, degrees) $(65 ; 19.0 \mathrm{~W}),(60 ; 2.5$ $\mathrm{W}),(55 ; 7.0 \mathrm{E})(50 ; 13.7 \mathrm{E})(45 ; 19.0 \mathrm{E}),(40 ; 23.3 \mathrm{E})(35 ; 26.9 \mathrm{E})(30 ; 30.1 \mathrm{E})$. These values were kindly calculated by David Sellers, using the algorithm given in Meeus (1989); see also http://www.phys.uu.nl/ vgent/venus/venus_text17.htm. Second contact $\left(t_{2}\right)$ would occurs about 18.5 minutes after first contact. The horizontal altitude lines are spaced by $5^{\circ}$, the $50^{\circ}$ North line passing through the tip of Cornwall. The vertical longitude lines are spaced by $5^{\circ}$. It takes the Sun 20 min to move $5^{\circ}$ in longitude. Take the $40^{\circ}$ latitude line as an example. Second contact would have just been visible in the heel of Italy at sunset, whereas observers in Mallorca could have seen Venus on the solar disc for an hour, in Madrid for $1 \mathrm{~h} 20 \mathrm{~min}$, and in Lisbon for $1 \mathrm{~h} 50 \mathrm{~min}$.

(1824 - 1910) painting of Horrocks observing the transit. Others (like Harriot) reduced the solar glare by observing near sunrise or sunset. Some also used tinted glass either in front of the telescopic objective or behind the eye lens. Many of them permanently damaged their eyesight.

Sunspot observations had been used to measure the spin of the sun and its rotation period of about $27 \mathrm{~d}$ (about a lunar month) about a fixed axis; this was of considerable fascination, especially as it is so much longer than the spin period of Earth. The next breakthrough, by Scheiner, was the discovery that the spin axis of the Sun was inclined at between $6^{\circ}$ and $8^{\circ}$ to the ecliptic. Most early observers commented on the fact that the spots were only to be found in a 'royal zone', a region that extended from the solar equator north and south to latitudes of about $30^{\circ}$. Early solar science culminated with the publication of Scheiner's Rosa Ursina, sive Sol ex admirando facularum et macularum suarum phenomeno varius in 1630.

After this the discoveries dried up. Think how long it was before William Herschel (1738 - 1822) measured the ratio between umbral and photospheric radiation, Claude-Sevais 


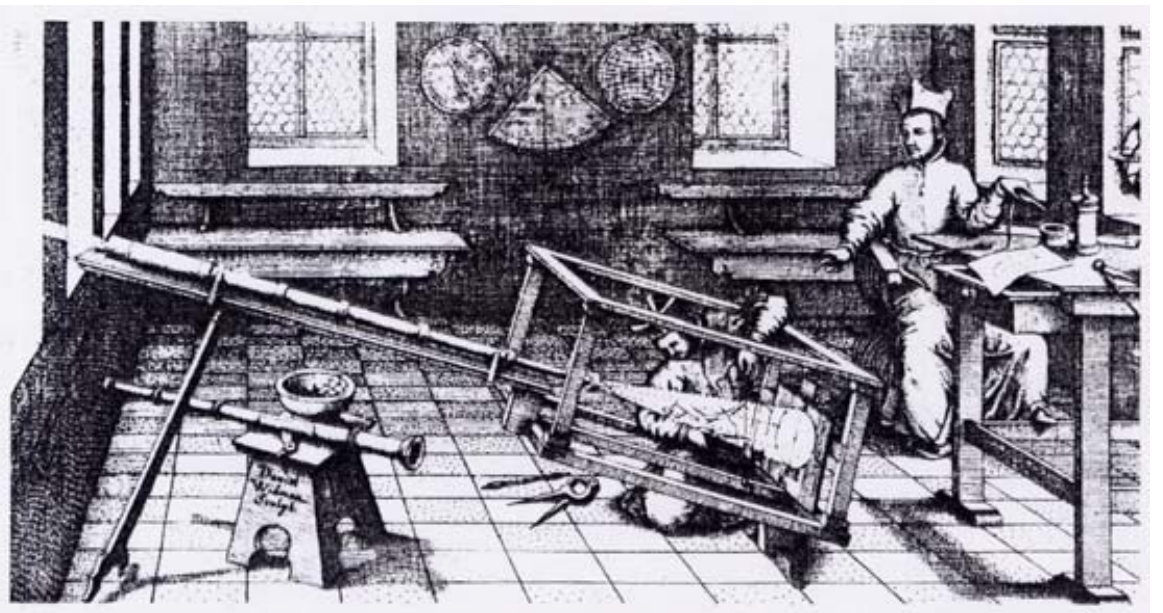

Figure 3. Father Christoph Scheiner $(1575$ - 1650) using a refracting telescope to project a solar image into an opaque screen. His assistant is apparently marking the positions of sunspots. This image was used as the basis of the Ford Madox Brown painting of William Crabtree observing the 1639 transit.

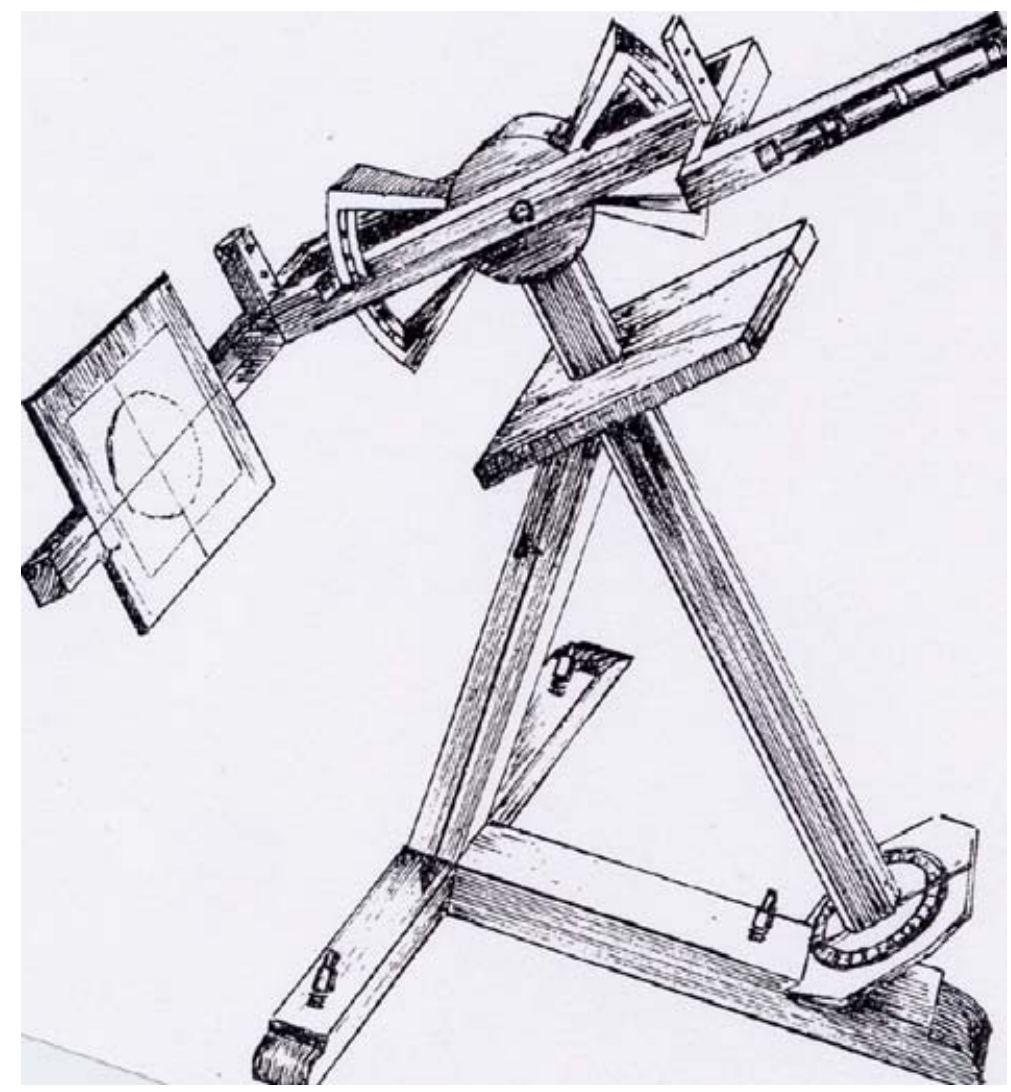

Figure 4. The Scheiner helioscope (see Rosa Ursina 1630) follows a principle introduced by Tycho Brahe and rotates about a polar axis. A reversed representation of this pioneering equatorial projection telescope was used in the Eyre Crowe $(1824$ - 1910) painting of Horrocks observing the transit, even though Horrocks probably used a system similar to that used by Crabtree. 
Table 2. Key astronomical dates in the vicinity of the Horrocks Venus transit; $1600-1677$

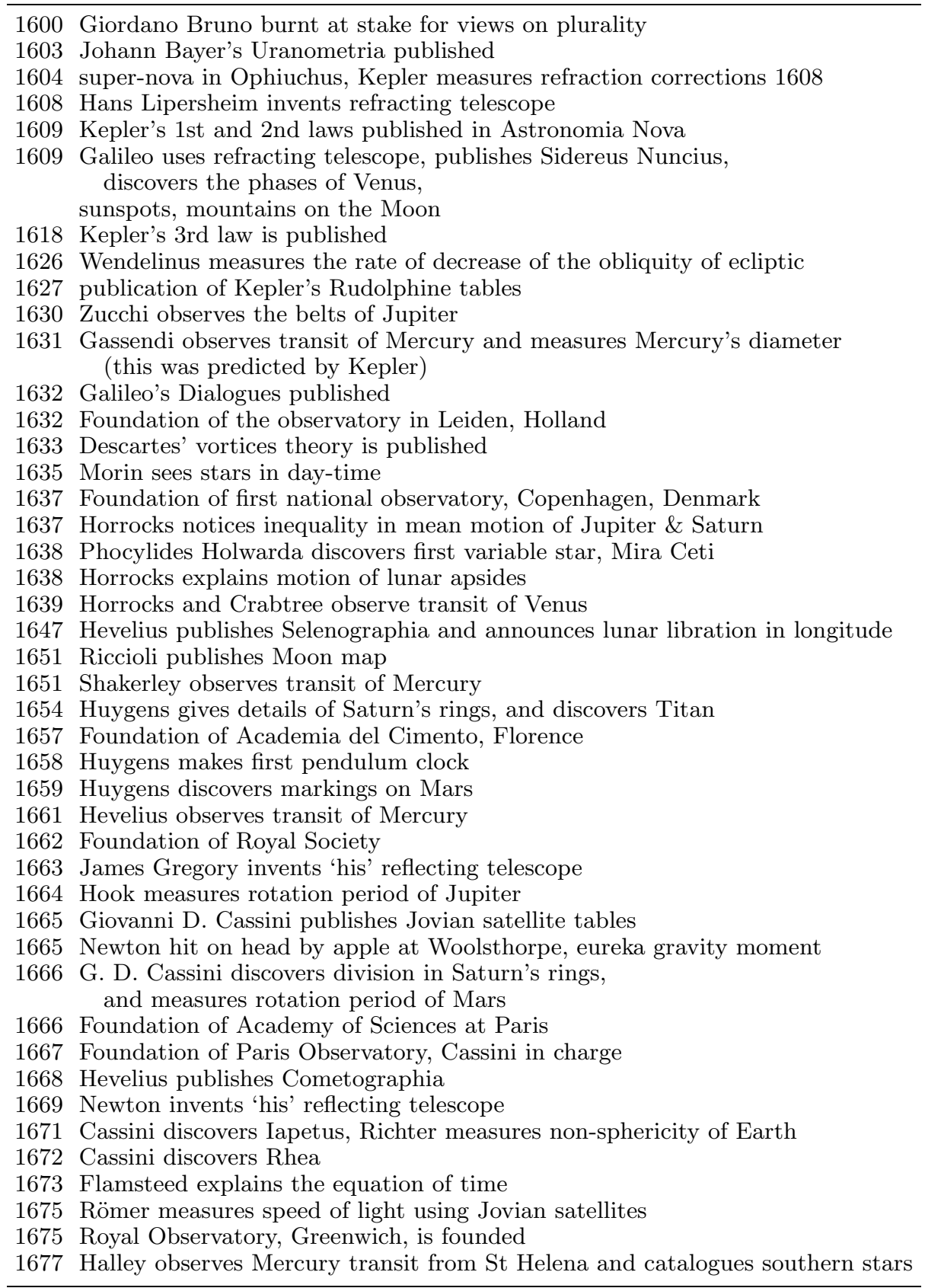

Pouillet (1790 - 1868) measured the solar radiation flux, Heinrich Schwabe (1789 - 1875) discovered sunspot periodicity in the 1843 and Richard Carrington (1826 - 1875) discovered the differential rotation of the Sun in the 1860s. After the 1609 - 1630 excitement solar research went cool and solar observations probably became less and less frequent. The sun was regarded as 'old hat'. On that December day in 1639 maybe only Horrocks and Crabtree were bothering to observe. To quote Meadows (1970), 'The initial burst 
of enthusiasm for solar observation, which followed the introduction of the astronomical telescope at the beginning of the seventeenth century, waned fairly quickly.' We might go so far as to suggest that the thirty-year interval between the first astronomical use of the telescope and the Venus transit of 1639 was ten years too long. If only the transit had taken place ten years earlier, or the telescope had been invented ten years later, many of the solar observers mentioned above might have been hard at work, observing the Sun at the transit time.

Returning to Fig. 2, however, it is worth noting that Scheiner, living as he was in Vienna, can hardly be blamed. And not only had the sun set for Galileo, in Florence, he had unfortunately gone blind in 1637. Godfrey Wendelin $(1580$ - 1660) in Belgium was also in the 'dark' zone. The main surprise is that the French did not see it. Forbes (1975) divides the contemporary French astronomical effort into three. There was a group in the south around Aix-en-Provence and Marseilles, including Joseph Gaultier, and Father Pierre Gassendi who concentrated on trying to make new celestial discoveries with telescopes. There was a Parisian school, which included Father Marin Mersenne, Etienne Pascal, and Blaise Pascal, who concentrated on mathematics and theoretical optics problems. And there were the Jesuits who concentrated on teaching and the writing and publication of astronomical textbooks.

(3) It was Sunday afternoon. Let us be rather contentious. There are two other reasons why European astronomers might be excused from seeing the Venus transit (Carole Stott, private communication, 2004). It occurred on a Sunday, the Lord's Day, the day of rest. Maybe the astronomers were at home with their feet up, relaxing after a hearty Sunday lunch. Also, anyone who was logging the disc movement and evolution of sunspots would observe the Sun as early as possible in the day, and make their recordings. After taking the daily readings they would then relax. Afternoon observations were probably less common than morning ones.

\section{Conclusions}

So the timing of the invention of the telescope, the speedy measurement of the 'easy' solar parameters, the growing realisation that the 1627 Rudolphine Tables were inaccurate, and the timing of Horrock's tabular work, his shyness and his uncertainly about his results, all conspired to give England in general and Lancashire in particular an amazing astronomical first.

\section{Acknowledgements}

I would like to thank David Sellers for the preparation of Fig. 2 and Carole Stott for her encouragement and comments.

\section{References}

Ferguson, James 1803 Astronomy Explained upon Sir Isaac Newton's Principles....11th Ed. J. Johnson et al., London, p. 491.

Forbes, Eric G. 1975 Greenwich Observatory, Volume 1: Origins and Early History (1675 - 1835 Taylor \& Francis, London, p. 4.

Knobel, E. B. 1903, The Observatory 26, 424-425.

Meadows, A. J. 1970 Early Solar Physics Pergamon Press, Oxford, p. 3.

Meeus, Jean 1989 Transits Willmann-Bell, Inc., Richmond, Virginia.

Wolf, A. 1968 A History of Science, Technology and Philosophy, Volume 1 George Allen \& Unwin Ltd, London, p. 79. 


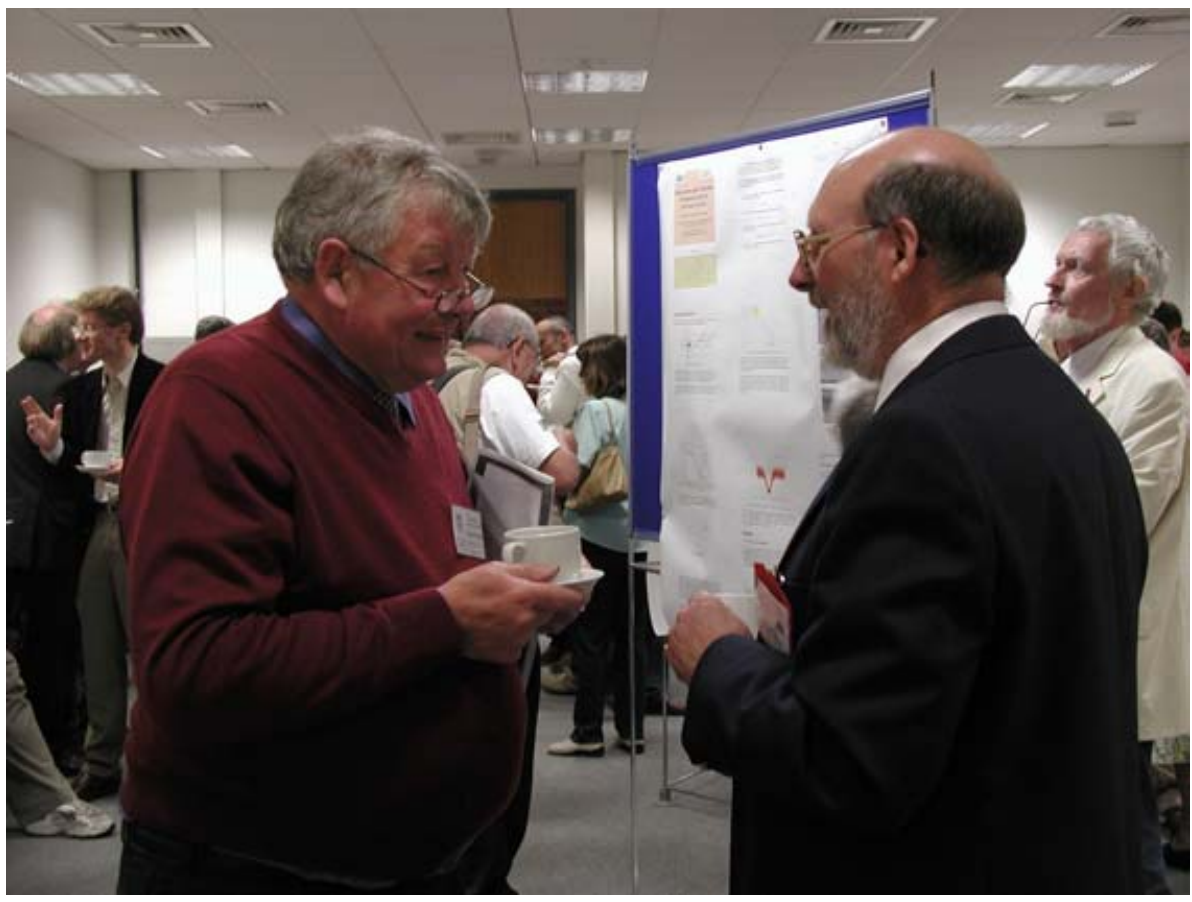

David Hughes and Wayne Orchiston

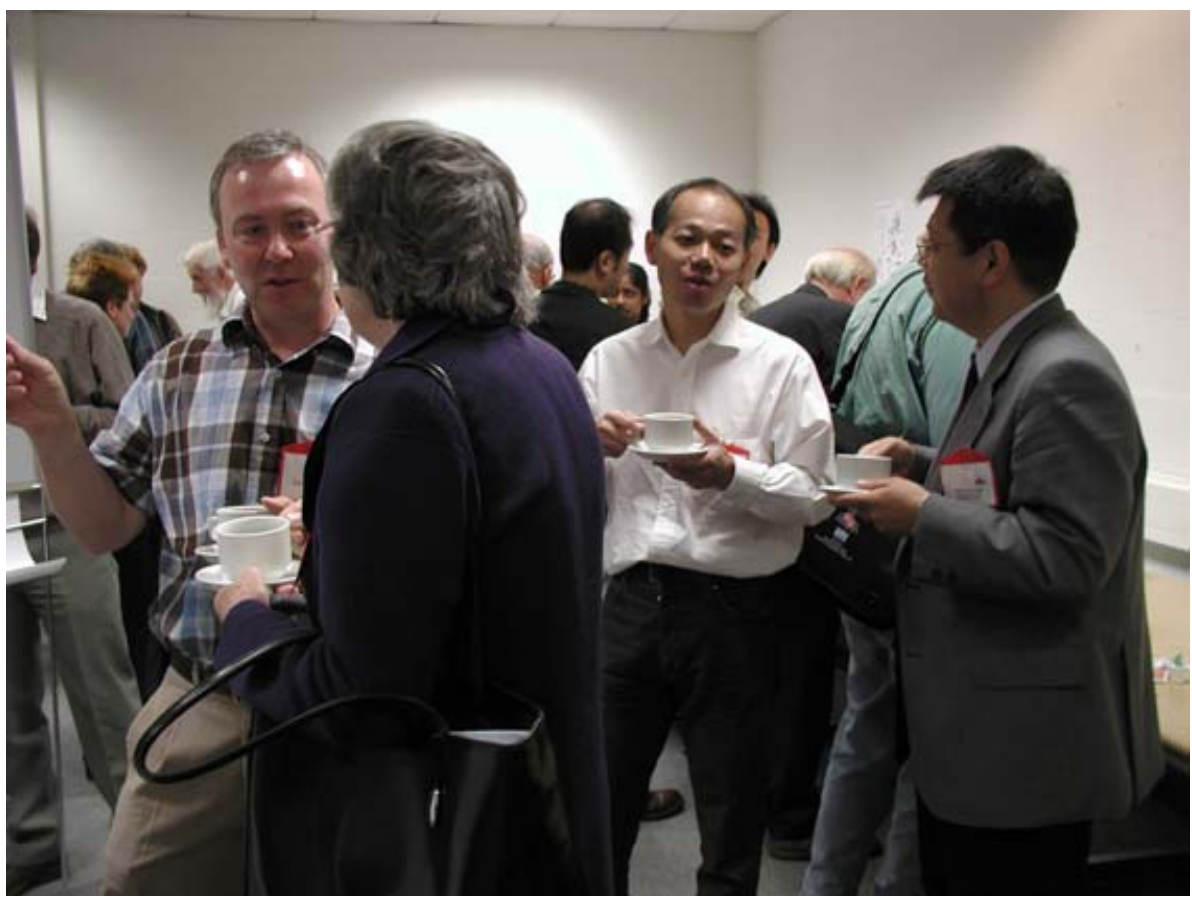

David Sellers discussing Lord Lindsay with Mary Brück; Takuji Tsujimoto and Naoteru Gouda 